\section{Saúde e ambiente no processo de desenvolvimento}

\author{
$\mathrm{H}$ ealth and the environment \\ in the development process
}

Prof. Dr. Milton Santos 1

(in memoriam)

\section{Conferência magna proferida no I Seminário Nacional Saúde e Ambiente no Processo de D esenvolvimento, em 12 de julho de 2000}

No ano de 2002 perdemos nosso grande companheiro M ilton Santos, intelectual brilhante, cuja obra seminal ultrapassou as fronteiras brasileiras e com certeza, influenciará ainda muitas gerações, na forma de pensar a geografia e a sociedade. A presença de Milton Santos na área da saúde se deveu muito a um movimento, que se intensificou na década de 1990, de articular os eventos e agravos aos espaços soci oculturais e econômicos nos quais acontecem. E também, se deve à clareza de seu pensamento sobre o lugar da ciência e da técnica na sociedade. Sua arguta capacidade crítica está presente no texto que vem abaixo, proferido em um dos eventos do Centenário da Fundação 0 swaldo Cruz.

A única justificativa para minha ousadia de estar aqui é o fato de que o que une as disciplinas todas é o mundo. E o mundo se havendo tornado acessível a todos nós, neste fim de século, fez que a filosofia se colocasse à disposição dos não filósofos, abrindo espaço para que a filosofia produzida em cada campo do saber seja operacional.

Acredito que o convite que me foi feito vem do fato de que não sou outra coisa senão um geógrafo. U m geógrafo que se dedicou ao longo da vida, com a sorte de viver até o fim do século, às coisas do mundo, agora que 0 mundo decidiu colocar-se ao al cance da nossa mão. I sso me permite al guns atrevimentos.

Primeiro, vai ser exatamente o de expor 0 que eu penso. 0 termo "meio ambiente" me incomoda profundamente. $N$ ão é uma questão corporativa; é que meio ambiente se constitui apenas uma metáfora, portanto não se pode teorizar a partir dessa noção. 0 que há é o mei o, que por simplificação às vezes se chama meio ambiente, o que constitui também uma redução. U ma redução que, como a expressão está dizendo, limita o raciocínio e pode trazer um perigo de equívoco que desejamos ultrapassar: ou seja, desejamos sair de uma acepção puramente técnica do viver e alcançar essa visão global sem a qual o humanismo pode ficar no discurso e ser portador de uma moralidade. 0 que distingue a moralidade é que ela éo fundamento da política, e nada se resolve a partir do domínio da técnica sem queo dado político seja posto em primeiro lugar. Quando eu falo em política não estou me referindo à política com 0 " $p$ " minúsculo da qual estamos desgraçadamente muito longe, mas àquela outra que é o desejo dos homens que pensam e que desejam e que pretendem, com o seu trabalho, melhorar o mundo para que mel hore o seu país e o seu lugar. $\mathrm{N}$ a realidade, a geografia, minha disci- 
plina, tem al gumas responsabilidades nisso, porque trabalhamos durante um século a partir da vertente européia, com visões que, na realidade, mais prejudicam que iluminam o debate da história do presente. U ma dessas visões é a visão do territóri o freqüentemente confundida com a visão do ambiente. $\mathrm{N}$ a realidade, território também não é uma categoria analítica. A categoria analítica é o território usado pel os homens, tal qual ele é, isto é, o espaço vivido pel os homens, sendo também, o teatro da ação de todas as empresas, de todas as instituições. D esse espaço humanizado, as cidades são hoje a grande representação e a grande esperança.

Eu queria fazer essa primeira consideração, pois ela se impõe para que não ten ha eu que recorrer, cada vez, a uma nota de pé-depágina.

A mensagem mais importante que gostaria de passar é que a busca da utopia é algo ancestral e companheiro do homem. 0 que distingue o ser humano dos outros animais não éo dedão, é exatamente o fato deque ele é portador de utopia. Eu sei que hoje se costuma ridicularizar quem fala em utopia, mas não me preocupo em insistir que sem ela não vale a pena viver, e sem ela também éimpossível pensar, porque o pensamento não é produzido a partir do que houve, nem do que há. 0 pensamento portador de frutos é produzido a partir do que pode ser. É isso que nos reúne aqui, nesta sala, e é isso que reúne os homens de boa vontade em toda a parte.

Ora, essa utopia secular, milenar, expressa de diferentes maneiras, pelas diferentes civilizações, codificadas pelos filósofos, tende a acabar com o século 20, que agora se esquiva dela graças ao fato de que o prometido casamento entre a técnica - isto é, modos de fazer - e a ciência - produção na mente dos modos de fazer a partir dos modos de ser - começa a setornar algo impossível.

Ora, os homens e mulheres, perdão, as mulheres e os homens que se ocupam da questão da saúde são, possivel mente, entre todos nós, aqueles que mais claramente se devotam à utopia, uma vez que cuidam do bemestar e da dignidade da vida humana. Esses sonhos e essas visões que el es e el as portam foram capazes de transformar a esperança dos cientistas no começo do século numa coisa viável, num presente construído a partir do pensamento científico.

A área da saúde é responsável por um be- lo momento da história da humanidade, belíssimo momento da história da ciência que buscou alicerçar as condições pelas quais a vida se tornaria não apenas mais Ionga, mas também mais digna de viver. Essa busca de possibilidades da medicina se baseou numa ciência em que houve um encontro entre preocupações morais e preocupações científicas.

A discussão presente na ética do trabalho do cientista não se imporia, como hoje, da forma que começa a se impor, exatamente porque o cientista era cautel oso diante do que produzia, difundia, propunha: a moral era a grande fiscal das realizações intelectuais. Isso também tinha relação com o fato de que o mercado que existia - já que o capitalismo, este breve momento da história da humanidade, dura 500 anos, por conseguinte, é mais veIho do que a institucional ização da ciência era circunscrito pelas frontei ras e regulado por um estado nacional. 0 mercado era um monstro domado, era um grande selvagem todavia domesticado. E as ideologias tinham livre curso, uma vez que as grandes revoluções foram presididas por grandes produções de idéias. As idéias filosóficas precediam a produções das idéias políticas, que precediam a produção da política.

Por isso hoje também, talvez, devamos levar em conta que uma idéia que brota aqui ou ali, e parece frágil num primeiro momento, pode ter força. Esse é o único alento que têm os que trabal ham intelectual mente: a consciência de que podem ficar sozinhos, porque sozinhos não estão, têm a companhia do futuro que ajudam a gestar através exatamente da produção de idéias generosas. As idéias libertárias e igual itárias e a ambição universalista levaram, depois da guerra, sobretudo, a que se tornassem gêmeas, as místicas do desenvolvimento e da civilização. É importante assinalar isso, porque, esse momento que tive a oportunidade de assi stir e viver, batal hando com tantos outros na busca dessa civilização nova, desse desenvolvimento que gan ha então uma expressão contraditória em relação ao crescimento econômico, essa distinção necessária entre os dois conceitos, é que vai marcar a história do mundo na metade do século 20.

Esse momento, por outro lado, é muito rico porque permite aflorar uma grande quantidade de postulações que leva ao debate mais filosófico da questão da vida. É aí queincluo a saúde. Evidente que a saúde pode ser tratada 
do ponto de vista técnico, mas é importante que o seja também do ponto de vista filosófico, subordinando as práticas e os recursos. É preciso lembrar que a palavra recurso não tem valor por si própria, el a é um termo do vocabulário da política. Cada vez que tratamos a questão dos recursos com autonomia, estamos abandonando a utopia, por conseguinte estamos renunciando a ser humanos.

Ora, a questão da saúde, como a da alimentação e a do bem-estar, foi no primeiro momento tratada segundo critérios deterministas. Essa é uma das razões pelas quais a palavra ambiente me choca, me aborrece. Com freqüência ela conduz a uma deriva determinista e por isso creio ser preciso retomar o debate na sua raiz. Foi essa questão do determinismo que levou, por exemplo, à conceituação das chamadas doenças tropicais. Tive há alguns anos um privilégio, digamos assim, de haver ensinado na U niversidade de Bordeaux, cujo Instituto de Geografia se chamava ou se chama Instituto de Geografia Tropical, como se hou vesse uma ciência social tropical e uma ciência social temperada. São formas de raciocínio próprias ao racismo, mais ou menos velado, dos europeus e que estão presentes também na vida acadêmica e na produção intelectual. É como se houvesse uma vontade de dizer: "as culpas das suas dores são suas. Nós pretendemos aliviá-las mas vocês são como são".

Essa idéia da geografia tropical foi que me conduziu a escrever um livro, do qual cada capítulo se tornou depois um novo livro, desmistificando o racismo implícito. Ele se chama 0 trabalho do geógrafo no Terceiro M undo. E hoje, devo dizer isso agora, esse livro éa crítica que eu fazia à geografia ensinada naquela faculdade. Essa idéia de doen ças tropicais que também levou a um certo paralelismo entre a noção de trópico e noção de uma higiene dificultada pela tropicalidade. $\mathrm{Da}$ mesma forma, a questão alimentar, quejá então preocupava as pessoas de boa vontade, também era apontada como um problema e uma questão da regionalização. Ou seja, haveria regiões fadadas a ter fome e outras fadadas a ter abundância. Critiquei a dicotomia racista e preconceituosa que considerava normal e evidente que os europeus se organizassem inteligentemente, e nós, naturalmente, em parte em culpa de nossa tropicalidade e em parte devido a nossa precariedade intelectual, não poderíamosultrapassar nossos limi- tes.

É aí que surge J osué de Castro, jamais suficientemente lembrado por nós. Ele teve a má sorte de morrer quando o Brasil era um país em pleno caminho para um regime autoritário e morrer na França, que, nesse momento abandonava sua vocação universalista. Então ele se foi sem o brilho que se costuma dar aos grandes homens quando eles desaparecem. E até hoje nós não conseguimos resgatá-Io condignamente. Quero dizer que osué de Castro sugeria uma mudança fundamental na visão do mundo e das coisas, inclusive na questão saúde, deslocando o problema do chamado ambiente e recolocando a questão no domínio da sociedade e da sociedade internacional. Razão pela qual ele acusava o O cidente do que hoje acusamos nós, isto é, essa vontade deliberada de genocídio através da vontade de poder. Não é de estranhar que Josué de Castro não tenha tido o prêmio N obel, geralmente outorgado a quem faz o possível para dar impressão que está cuidando da humanidade.

A idéia da natureza natural iria nos perseguir permanentemente. A história comprova que a natureza natural tem um papel, evidentemente. Ninguém vai desconhecer, no entanto, que el e não é central na história; sobretudo hoje, cada vez menos. Ao mesmo tempo, a universidade era marcada pelo livrepensar - coisa que cada vez é menos - e a cooperação internacional, em matéria de pensamento, era possível. Nós sabemos que hojeé quase impossível cooperar com os nossos colegas do N orte, por motivos que não vou analisar agora, porque as nossas universidades nos pedem que sejamos cada vez mais amiguin hos dos colegas de lá para aumentar os nossos títulos. Então somos convidados a um expediente de safadeza cotidiano para obter as promoções. Não sei o que acontece no Equador, Cuba, mas no Brasil é muito freqüente que o que você faz seja diferenciado pelas categorias "nacional" e "internacional". Ou seja, o que se faz aqui nunca é internacional? Equivocadamente os val ores são atribuídos a quem poderia ser transferido para o $\mathrm{M} \mathrm{i-}$ nistério do Turismo em vez de permanecer no M inistério da Educação ou da Ciência e Tecnologia.

Essa época que estamos viven do nos leva à necessi dade de imbricação crescente de várias questões e a uma vontade de teorizar, que se mostra necessária em todos os domínios: teo- 
rizar a população, teorizar a urbanização, teorizar a nutrição, teorizar a saúde pública, teorizar o desenvolvimento. Essas teorias, tempos atrás, eram imbricadas umas com as outras porque 0 elo central era exatamente 0 mundo, que é a unidade de pensamento de problemas. M as hoje tudo o que era baseado numa solidariedade internacional e numaluta civilizatória deixou de existir.

Daí a contribuição fundamental à questão da saúde, dada por desenvolvimentistas, terceiro-mundistas, antiimperialistas, no fim dos anos 60 e no começo dos anos 70. Perdoem-me os que são muito jovens, pois até eu "cometi" um livro, que não está traduzido para o português, que discute a questão da alimentação e da população, evidentemente passando pela questão da saúde, a partir de uma visão de um geógrafo. É dessa época também que se notam progressos médicos conducentes a uma melhor saúde individual e coletiva, havendo avanços, ainda que não homogêneos, na questão da prevenção, da informação e de uma tomada de consciência. Então, a ajuda internacional tinha um papel positivo. A partir dos anos 70, em grande parte, essa ajuda se deixa comandar por interesses das grandes potências. Basta ver o tratamento dado à questão da fome, na África subsaariana comandada pela política dos novos grandes impérios. Também é o mesmo caso do tratamento de diversas questões no subcontinente asiático, consideradas como ajuda internacional, mas tratadas de forma egoística, de tal maneira que as pessoas bem pensantes passaram, desde então, a desconfiar da palavra "ajuda". M as também vivenciamos a timidez das idéias provenientes das instituições internacionais, a prudência com a qual os seus representantes tomam a palavra nas ocasiões que Ihe são ofereci das, o escamoteamento da centralidade do problema social e político mundial, a prevalência dos enfoques tecnicistas que também dominam si tuações de grande relevo para a vida do ser humano, como éo caso também na própria medicina em todos os seus aspectos. Essa última mostra o distanciamento entre uma produção intelectual que se amplia e para a qual os recursos são abundantes, desde que, os esforços se dirijam nesta "direção vesga", e a realidade que avoluma problemas que necessitam de enfoques mais abrangentes.

$N$ aquele tempo gabávamo-nos dos efeitos das políticas, mas também dos efeitos do de- senvolvimento sobre os índices vitais, mortalidade geral, mortalidade infantil, fertilidade, esperança de vida e nutrição. Buscávamos essa combinação entre minorias e condições gerais e efeitos do desenvolvimento sobre a vida individual e das famílias. Esses anos 70 marcam a emergência tímida e depois agressiva de aspectos chamados qualitativos. M as todo mundo sabe que o qualitativo rapidamente mostra-se com sua cara quantitativa, portando variáveis novas, dentre as quais a tecnociência que tem um papel desgraçadamente muito importante nas questões que interessam a área da saúde.

Esses progressos da ciência e da técnica estimularam a produção pragmática, ou seja, vamos fazer assim para obter tal resultado. A tal ponto isso se generalizou que as formulações ditas gerais começam do resultado e não das causas, o que é sempre um empobrecimento do ponto de vista da posição do pensamento. Essa pragmática coloca os resultados à prova, como algo a desejar, mostrados como se fossem algo moral. Inclusi ve essa questão do meio ambiente freqüentemente é mal colocada, já que as dificuldades da mai or parte da população não vêm do fato de estar aqui e ali, mas do fato de ser assim ou assado.

U m saber e uma prática bem descolados de preocupações humanísticas são a principal marca do domínio da técnica sobre a ciência que estamos agora assistindo: é a técnica que também está ditando as escolhas possíveis dos remédios.

É curioso que a nova ciência semi-imposta pela via da técnica, pelos portadores de uma filosofia pragmática, vem sobretudo dos Estados U nidos que hoje têm o comando absoluto do debate das questões, por exemplo de saúde, tanto do ponto de vista social quanto individual. Isso se dá em paralelismo com a busca de uma nova ordem da economia. Q uando os progressos técnicos científicos ganham autonomia - e é ao que estamos assi stindo hoje na vida acadêmica com profundas repercussões negativas na produção da políti$\mathrm{ca}$-, eles ten deriam a aconsel har ou justificar visões de buscas parciais, cada vez mais parciais; cada vez mais profundas e mais parciais, cada vez mais penetrantes e cada vez mais parciais; cada vez mais isoladas e cada vez mais autônomas. Dessa forma a produção de conhecimento gan ha autonomia sobre a vontade de humanização da vida sobre o planeta.

Sou apenas um observador das questões 
médicas; quem sou eu para ter um juízo definitivo ou mesmo próximo disso. A respeito disso confesso que tenho muito medo do que leio, sobretudo; sou um homem assustado porque chego à idade que tenho quase com a obrigação de ser também doente. Vejo-me cada dia cotejado com manchetes contraditórias dentro das mesmas revistas, dando conta do trabalho já não tanto das universidades mas das empresas, ou então, das empresas dentro das universidades. A grande moda agora épedir às universidades que perguntem às em resas que digam o que elas devem fazer. É considerado chique e permite ao CN Pq se retirar do processo de financiamento. Só que, na produção de dados que têm relação com a vida, o resultado pode ser a corrupção da pesquisa e a desconfiança justificada em rel ação aos homens de ciência.

U ma meia verdade serve a objetivos pragmáticos, mas uma meia verdade não é a verdade. $E$ todas as meias verdades possíveis reunidas não produzem a verdade. As verdades parciais podem ser eficazes no interesse daqueles a quem interessem, mas não conduzem à verdade, e cedo ou tarde conduzirão a desastres. Tal é o caso do Brasil, cujo primeiro grande desastre vai se manifestar no setor da saúde. Aliás já está se mostrando, exatamente porque esse modelo foi aceito tranqüilamente pelo Estado e também por nós da universidade, por nós os cientistas que não levantamos suficientemente a voz para protestar. Isso tem que ser dito: essa "universidade de resultados" com esse autocontrole suicida, mas também assassino dos cientistas, dá prioridade à elaboração dos textos, ao poder eao mercado, um círculo fechado.

É evidente que as questões técnicas do "como fazer" são importantíssimas, mas que faço delas se não obtiver antes esse dia mais amplo de recolocá-las dentro de um quadro, no qual as coisas todas possam ser cotejadas, revistas, produzindo uma idéia generosa da convivência entre os homens, uma idéia generosa do que o mundo pode ser? Isso é responsabilidade nossa como intel ectuais.

A globalização vai deixando para trás as grandes questões civilizatórias, humanísticas; basta ver o debate que se dá no Brasil atual, e no qual a palavra civilização é quase obscena também para os adultos. O u seja, não está proibida apenas aos menores de 14 ou 16 anos, é uma pal avra que se tornou proibida neste país. É grave que esse reducionismo não seja apenas um dado do oficialismo, é também um dado das oposições. Eu ia dizendo das esquerdas, poderia insistir nisso somente acrescentando que ser esquerda hoje é de novo ser diferente de ser direita, só que a direita dá central idade a isso que passamos a adorar, a moeda estável, o fim da inflação, os equilíbrios macroeconômicos, repetindo sempre o mesmo sem saber para que e por que. E a esquerda seria aquela parte da sociedade preocupada com essa coisa tão insignificante, mas que configura a única justificativa real para que o mundo prossiga: o homem.

A globalização veio sem que se viesse junto um mundo só. Busca-se abreviar o tempo do trabal ho, mas não é para socializar o lazer, é pra fazê-lo ainda mais mercantil. Acreditase que a técnica conduz ao desemprego. Que horror! A técnica jamais existiu historicamente sem a política. É um equívoco imaginar que se poderia conceber a presença histórica da técnica sem o paralelo da política. É a política que decide o que fazer da técnica: em todos os tempos foi assim. Inventam-se novas formas construtivas, mas não para humanizar a cidade. $O$ u seja, não éa cidade que éresponsável pelos problemas, como tantas vezes se diz. A urbanização não éum mal.

A urbanização permitiu avanços formidáveis em todas as áreas, inclusive da saúde. $N$ ão foi por causa da urbanização que os países subdesenvolvidos tiveram muitas dificuldades para enfrentar as questões de saúde, tanto do ponto de vista individual quanto do ponto de vista coletivo. É a maneira como organizamos a sociedade, separando os que podem e os que não podem viver em determinados lugares. $M$ as, em geral não queremos falar em mudanças sociais, queremos falar das mudanças dos organogramas. Daí esse enfoque tímido e de subserviência ao sistema e que, geralmente, dá prioridade ao que não tem, à falta e ao que deve ser suprido.

Nos anos 60 e 70, a grande luta era para aumentar a produção al imentar. Aí, nos anos 70 houve os que toleraram a revolução verde. Agora há os que estão justificando os transgênicos, como se a questão da fome e todas as questões sociais fossem derivadas de soluções técnicas. Vimos que, primeiro a produção alimentar ultrapassou a necessidade alimentar do mundo tomado como um todo, basta ver o ardor com que os europeus arrancam as suas plantações al imentares para garantir o preço. Portanto, a questão não é técnica, é de econo- 
mia política, de distribuição do poder e da riqueza. No caso das doenças, não são os anais dos congressos que determinam como elas vão ser tratadas e sim o poder econômico que privilegia uma parte da sociedade em detrimento da outra.

A discussão que agora timidamente se dá no Brasil quanto à distribuição dos remédios ébem explicativa dessa situação. I sso tem que ver, em grande parte, com o fato de que a técnica passou a ter comando sobre a ciência, $e$ como a técnica é cada vez mais comandada pelo mercado, é tam bém o mercado que comanda a ciência. Os estudiosos da área da saúde sabem disso melhor do que eu, porque a minha disciplina não me obriga a produzir produtos, somente idéias, enquanto eles são obrigados a produzir produtos-resultados.

A cidade está ameaçada de privatização, o que vai ser um grande problema nas questões de saúde pública. N a nossa análise está faltando - na dos profissionais de saúde e na dos geógrafos - uma análise prospectiva desse processo de privatização que vai agravar ainda mais questões de saúde pública: a privatização da água, dos esgotos, e tudo mais que concerne à vida urbana. No mundo em que a cidade, tendo crescido de tamanho, tem nas empresas filiadas aos grandes bancos a solução para as questões urbanas, na medida em que são cegos para a vida social e para as questões humanitárias, os problemas vão se avolumar contra os que não podem pagar.

Será que essa técnica, assim comandante da ciência, essa técnica assim comandada pelo mercado, esse mercado comandante da ciência decretaram uma vez por todas a maldição dos homens de ciência ou podem eles ainda erguer a sua cabeça, e dizer: não! Espe- ro que essa famosa lista com que os congressos terminam inclua os grandes problemas de sociedade que em um país como Brasil têm gravidade irrecusável. Aí comparece o papel crítico e que tem de ser de grande valentia, das ciências humanas, e entre elas, das ciências sociais da saúde.

É evidente que a estrutura da universidade atual é hostil a qualquer exercício do pensamento livre. Esse, talvez, seja o maior problema da universidade brasileira. O u seja, o maior desmentido da universidade pública brasileira, que se quer pública, mas não chega a sê-lo e não o é. Considero que o pensamento que se el abora em nossas universidades públicas é cada vez menos público, porque cada vez menos livre. Por conseguinte, já que me convidaram, eu Ihes venho fazer esse apelo, evidente que nem precisava fazê-lo, porque essas idéias estavam presentes nas mentes e nos corações. Todavia, é sempre bom que alguém venha e produza algum discurso de conjunto, oferecendo uma provocação que amplie as vozes e que, eventualmente, as façam entendidas. As vozes não são entendidas quando se dirigem às autoridades, esse tempo acabou. As vozes têm de se dirigir à sociedade em geral, que se incumbe depois de impor aos ouvidos das autoridades. Ela condiz com o que profundamente sentem as pessoas. Quero falar sobre a esperança que os senhores me dão, e com a esperança me despeço. 